\title{
Modified high-flow nasal cannula oxygen therapy versus conventional oxygen therapy in patients undergoing bronchoscopy: a randomized clinical trial
}

Rui Wang ${ }^{\dagger}$, Hai-Chao Li ${ }^{\dagger}$, Xu-Yan Li, Xiao Tang, Hui-Wen Chu, Xue Yuan, Zhao-Hui Tong and Bing Sun ${ }^{*}$

\begin{abstract}
Background: Hypoxemia frequently occurs during bronchoscopy. High-flow nasal cannula (HFNC) oxygen therapy may be a feasible alternative to prevent the deterioration of gas exchange during bronchoscopy. With the convenience of clinical use in mind, we modified an HFNC using a single cannula. This clinical trial was designed to test the hypothesis that a modified HFNC would decrease the proportion of patients with a single moment of peripheral arterial oxygen saturation $\left(\mathrm{SpO}_{2}\right)<90 \%$ during bronchoscopy.
\end{abstract}

Methods: In this single-center, prospective randomized controlled trial, hospitalized patients in the respiratory department in need of diagnostic bronchoscopy were randomly assigned to a modified HFNC oxygen therapy group or a conventional oxygen therapy (COT) group. The primary outcome was the proportion of patients with a single moment of $\mathrm{SpO}_{2}<90 \%$ during bronchoscopy.

Results: Eight hundred and twelve patients were randomized to the modified HFNC $(n=406)$ or COT $(n=406)$ group. Twenty-four patients were unable to cooperate or comply with bronchoscopy. Thus, 788 patients were included in the analysis. The proportion of patients with a single moment of $\mathrm{SpO}_{2}<90 \%$ during bronchoscopy in the modified HFNC group was significantly lower than that in the COT group $(12.5 \%$ vs. $28.8 \%, p<0.001)$. There were no significant differences in the fraction of inspired oxygen between the two groups. The lowest $\mathrm{SpO}_{2}$ during bronchoscopy and 5 min after bronchoscopy in the modified HFNC group was significantly higher than that in the COT group. Multivariate analysis showed that a baseline forced vital capacity $(\mathrm{FVC})<2.7 \mathrm{~L}(\mathrm{OR}, 0.276 ; 95 \% \mathrm{Cl}, 0.083-0.919$, $p=0.036)$ and a volume of fluid instilled $>60 \mathrm{ml}(\mathrm{OR}, 1.034 ; 95 \% \mathrm{Cl}, 1.002-1.067, p=0.036)$ were independent risk factors for hypoxemia during bronchoscopy in the modified HFNC group.

Conclusions: A modified HFNC could decrease the proportion of patients with a single moment of $\mathrm{SpO}_{2}<90 \%$ during bronchoscopy. A lower baseline FVC and large-volume bronchoalveolar lavage may predict desaturation during bronchoscopy when using a modified HFNC.

\footnotetext{
*Correspondence: ricusunbing@126.com

${ }^{\dagger}$ Rui Wang and Hai-Chao Li contributed equally to this study Department of Respiratory and Critical Care Medicine, Beijing Chao-Yang Hospital, Beijing Institute of Respiratory Medicine, Beijing Key Laboratory of Respiratory and Pulmonary Circulation Disorders, Beijing Engineering Research Centre for Diagnosis and Treatment of Respiratory and Critical Care Medicine (Beijing Chao-Yang Hospital), Capital Medical University, No. 8 Gongtinan Road, Chaoyang, Beijing 100020, China
} permits use, sharing, adaptation, distribution and reproduction in any medium or format, as long as you give appropriate credit to the original author(s) and the source, provide a link to the Creative Commons licence, and indicate if changes were made. The images or other third party material in this article are included in the article's Creative Commons licence, unless indicated otherwise in a credit line to the material. If material is not included in the article's Creative Commons licence and your intended use is not permitted by statutory regulation or exceeds the permitted use, you will need to obtain permission directly from the copyright holder. To view a copy of this licence, visit http://creativecommons.org/licenses/by/4.0/. The Creative Commons Public Domain Dedication waiver (http://creativecommons.org/publicdomain/zero/1.0/) applies to the data made available in this article, unless otherwise stated in a credit line to the data. 
Trial registration ClinicalTrials. Gov: NCT02606188. Registered 17 November 2015.

Keywords: Modified high-flow nasal cannula oxygen therapy, Conventional oxygen therapy, Bronchoscopy, Hypoxemia

\section{Bacjground}

Bronchoscopy has an important role in diagnosing and treating respiratory diseases and is now a useful tool to investigate abnormal pulmonary lesions [1]. Hypoxemia frequently occurs during bronchoscopy [2]. The partial pressure of arterial oxygen $\left(\mathrm{PaO}_{2}\right)$ usually decreases by 10-20 mmHg during bronchoscopy [3], and bronchoalveolar lavage (BAL) is associated with an even greater decrease [4]. A previous report showed that oxygen therapy is required in $24 \%$ of patients during bronchoscopy [5].

To avoid bronchoscopy-induced hypoxemia, patients generally require oxygen therapy via a nasal cannula to maintain an arterial oxygen saturation $\left(\mathrm{SaO}_{2}\right)>90 \%$ during bronchoscopy [6]. Nasal cannulas supply oxygen based on the patient's respiratory pattern, which limits their use. Compared with conventional oxygen supplementation, noninvasive ventilation (NIV) is known to prevent gas exchange deterioration during bronchoscopy in hypoxemic patients [7, 8]. However, NIV is seldom used because it is associated with ace mask intolerance, the difficulty of introducing the bronchoscope to the nares due to the face mask, and further complicated by the occurrence of patient-ventilator asynchrony, which may increase patients' discomfort and intolerance.

High-flow nasal cannula (HFNC) oxygen therapy provides accurate oxygen delivery, wash-out of the anatomic dead space, and a low level of positive pressure [9]. HFNC is easy to use and well tolerated. Thus, HFNC therapy could be used as a new choice for oxygen therapy during bronchoscopy. Recently, HFNC has been shown to improve oxygenation in acute respiratory failure patients undergoing bronchoscopy [10-13]. In our center, the bronchoscope was passed through the nose during all procedures. HFNC oxygen therapy is applied to both nostrils. The bronchoscope occupies one of the nares receiving oxygen therapy during bronchoscopy. As a result, the application of HFNC needs to be optimized. We therefore designed a modified HFNC that has a single cannula.

We hypothesized that, during bronchoscopy, modified HFNC oxygen therapy may maintain oxygenation better than conventional oxygen therapy (COT). Therefore, we conducted a prospective randomized controlled study to determine whether a modified HFNC could decrease the proportion of patients with a single moment of peripheral arterial oxygen saturation $\left(\mathrm{SpO}_{2}\right)<90 \%$ during bronchoscopy.

\section{Methods \\ Study design and patients}

This was a single-center prospective randomized controlled trial (ClinicalTrials.gov, NCT02606188). Patients were recruited from the general wards of the Respiratory Department at Beijing Chao-Yang Hospital. This study was approved by the Ethics Committee of the Affiliated Beijing Chao-Yang Hospital, Capital Medical University (2015-KE-85), and informed consent was obtained from all patients or their legal guardians in writing.

We included patients who met the following criteria: (1) age more than 18 years old; and (2) indication for diagnostic bronchoscopy. Patients with any of the following criteria were excluded: (1) $\mathrm{SpO}_{2}<90 \%$ on room air; (2) platelet count $<60 \times 10^{9} / \mathrm{L}$; and (3) nasopharyngeal obstruction or blockage.

\section{Randomization}

At the time of admission, eligible patients were randomly assigned to the modified HFNC oxygen therapy group or the conventional oxygen therapy (COT) group for respiratory support during bronchoscopy. A randomization list in blocks of four was generated from a computer, and the treatment allocation was concealed using sequentially numbered, opaque, sealed envelopes. All nurses and other research personnel were blinded to the randomization schedule and block size.

Data collectors were aware of the study group assignments, but the analyses were performed by a research statistician who did not participate in the investigation and did not know the research groupings. Because of the nature of the intervention, physicians and nurses could not be blinded to the group assignments.

\section{Interventions}

In the modified HFNC group, high-flow devices $\left(\right.$ AIRVO $^{\mathrm{TM}} 2$; Fisher \& Paykel Healthcare, Auckland, New Zealand) were utilized for respiratory support. The nasal cannula used was a modified single nasal cannula. The modified HFNC was shown to have similar respiratory support characteristics as the regular HFNC in in vitro experiments (Additional file 1). The size of the nasal cannula was chosen based on the patient's nostrils. The fraction of inspired oxygen $\left(\mathrm{FiO}_{2}\right)$ was adjusted to maintain 
an $\mathrm{SpO}_{2}>90 \%$. The humidifier temperature was set to $37^{\circ} \mathrm{C}$, and the oxygen flow was set to $50 \mathrm{~L} / \mathrm{min}$.

In the COT group, oxygen was delivered via nasal prongs during bronchoscopy. The oxygen flow was set to achieve an $\mathrm{SpO}_{2}>90 \%$. COT provides $24 \%-45 \%$ oxygen with flow rates up to $6 \mathrm{~L} / \mathrm{min}$, although the patient's respiratory pattern can influence the actual $\mathrm{FiO}_{2}$ [14]. We used a simple formula to estimate the $\mathrm{FiO}_{2}$, as follows: each $1 \mathrm{~L} / \mathrm{min}$ of nasal $\mathrm{O}_{2}$ increased the $\mathrm{FiO}_{2}$ by approximately $4 \%$.

In both groups, caregivers adjusted the $\mathrm{FiO}_{2}$ before hypoxemia occurred during bronchoscopy. The trigger to adjust the $\mathrm{FiO}_{2}$ was an $\mathrm{SpO}_{2}$ drop to $93 \%$, and there was a downward trend. After bronchoscopy, patients continued to be given COT when $\mathrm{SpO}_{2}$ was $<90 \%$.

\section{Flexible bronchoscopy and BAL}

All bronchoscopy procedures were performed by three respiratory specialists, each with $>10$ years of experience. Electrocardiogram (ECG), heart rate, respiratory rate, and $\mathrm{SpO}_{2}$ were recorded continuously by a bedside ECG monitor. The data collector recorded the vital signs on the paper case report form (CRF) after determining their authenticity. The data collector judged whether the vital signs were accurate based on their waveform and the patient's condition (e.g., agitation). If the data collector considered the vital signs to have artifacts, the patient was allowed to stabilize for a certain amount of time before re-recording. Blood pressure was monitored automatically and noninvasively every $5 \mathrm{~min}$. Hypoxemia events were defined as $\mathrm{SpO}_{2}<90 \%$ at a single time point. The worst values during bronchoscopy meant the lowest $\mathrm{SpO}_{2}$, highest $\mathrm{FiO}_{2}$, highest respiratory rate, highest heart rate, and highest mean arterial pressure.

The setup using modified HFNC oxygen therapy or COT is illustrated in Fig. 1. Patients in our study were given topical anesthesia, but no sedative was used. For topical anesthesia, $2 \%$ lidocaine was nebulized into the nasal cavity and pharyngeal mucosa. For all patients, a resting period of approximately $5 \mathrm{~min}$ was required for the local anesthesia to fully take effect. Bronchoscopy was performed transnasally with the patient in the supine position. The bronchoscope was inserted in the trachea, and then $10 \mathrm{ml}$ of lidocaine was sprayed into the left and right main bronchi in aliquots of $5 \mathrm{ml}$. The bronchi were examined, and the bronchoscope was wedged into the appropriate segmental bronchus. BAL was performed using normal saline instilled in aliquots of $20 \mathrm{~mL}$ and

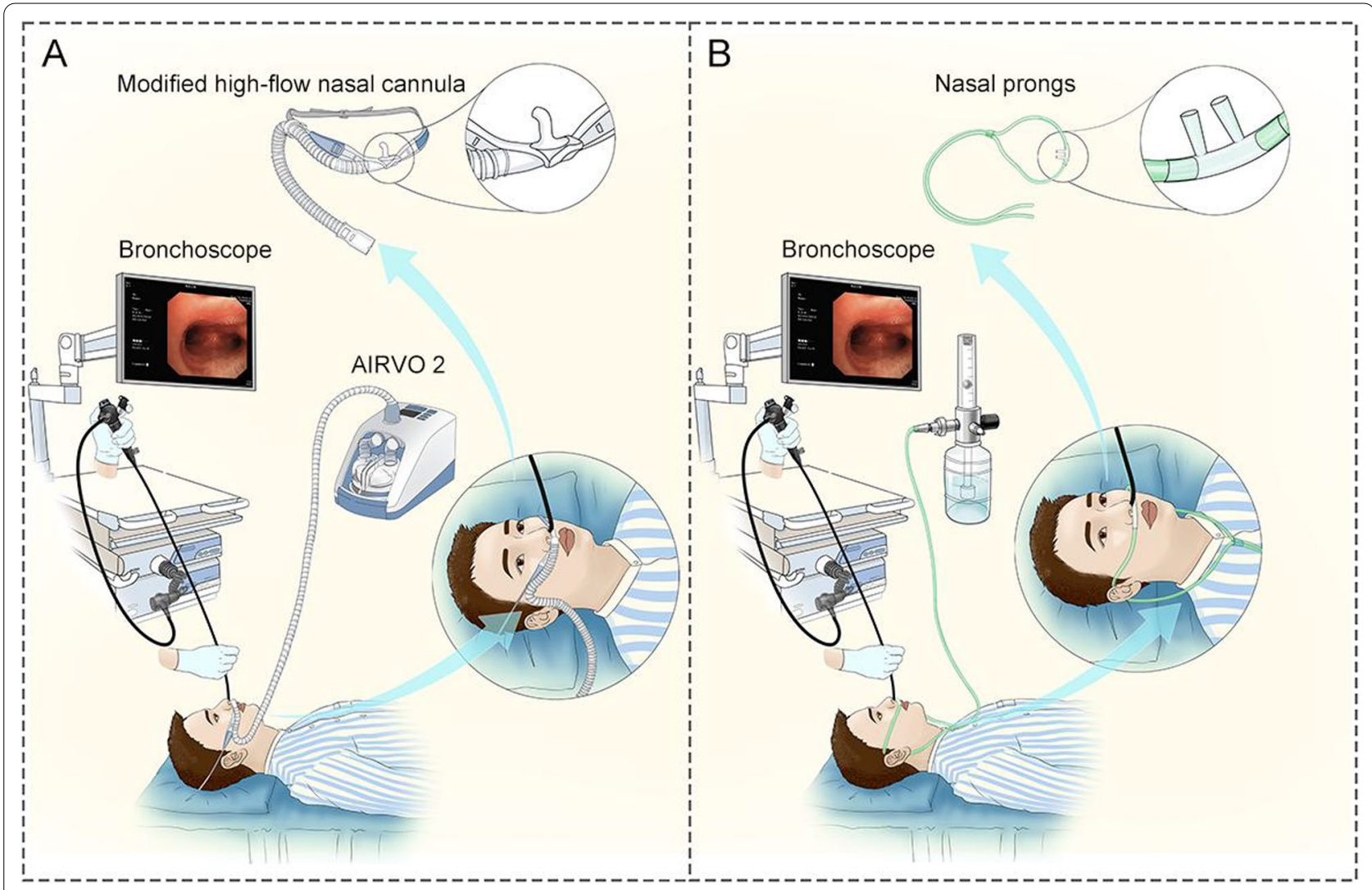

Fig. 1 Illustration of bronchoscopy using a modified HFNC (A) or COT (B). HFNC high-flow nasal cannula, COT conventional oxygen therapy 
then aspirated. The volume of BAL instilled depended on the category of disease and the patient's condition. BAL fluid was sent for cytologic or microbiologic analysis.

The events during bronchoscopy included agitation, bronchospasm, arrhythmias, hypertension, epistaxis, and mucosal bleeding. Four main groups of arrhythmias, namely, extra beats, supraventricular tachycardias, ventricular arrhythmias, and bradyarrhythmia, were recorded. Hypertension was defined as systolic blood pressure $>180 \mathrm{mmHg}$.

The complications of bronchoscopy include fever, pneumothorax, and hemorrhage. A fever is defined as a temperature $>38^{\circ} \mathrm{C}$ within the first $24 \mathrm{~h}$ after bronchoscopy [15]. Transient fever, which spontaneously resolves within $24 \mathrm{~h}$, is the most common adverse event after BAL is performed. After a transbronchial lung biopsy was performed, a chest radiograph was routinely performed to determine whether the patient had a pneumothorax. In the case of significant pneumothorax, a chest tube was immediately inserted to avoid oxygen desaturation or tension physiology. Hemorrhage requires topical instillation of small amounts of adrenaline solution or more advanced interventions.

If the $\mathrm{SpO}_{2}$ persisted at $<90 \%$, the examination was aborted or discontinued at the discretion of the bronchoscopist. Restart the procedure after the $\mathrm{SpO}_{2}$ has been restored to $90 \%$.

\section{Endpoints and measurements}

The primary endpoint was the proportion of patients with a single moment of $\mathrm{SpO}_{2}<90 \%$ during bronchoscopy. The secondary endpoint was the duration of bronchoscopy, which was defined as the time between insertion and removal of the bronchoscope from the tracheobronchial tree [10]. Other endpoints were duration of $\mathrm{SpO}_{2}<90 \%$ and the proportion of patients with procedural discontinuation. Other variables included the following: (1) demographic variables; (2) vital signs and $\mathrm{FiO}_{2}$ before bronchoscopy, the worst values during the procedure and within $24 \mathrm{~h}$ after bronchoscopy; and (3) bronchoscopy-related events and complications.

\section{Statistical analysis \\ Sample size estimation}

A sample size of 390 participants per group was chosen to have $80 \%$ power to demonstrate that the modified HFNC group was superior to the COT group for the primary measure (proportion of patients with an $\mathrm{SpO}_{2}<90 \%$ during bronchoscopy), with the use of a margin of 0.08 based on an observed $28 \%$ of patients with an $\mathrm{SpO}_{2}<90 \%$ during bronchoscopy for the COT group in a previous study and an assumed $20 \%$ for the modified HFNC group [16].

\section{Comparisons of the two groups}

The results for continuous variables are shown as either means ( \pm standard deviation) or medians (with interquartile ranges). Groups were compared using either Student's $t$ test or the Mann-Whitney $U$ test, as appropriate. For categorical variables, the percentage of patients in each category was compared using a chi-square test or Fisher's exact test. The overall time course for vital signs and $\mathrm{FiO}_{2}$ was compared using two-way analysis of variance for repeated measures.

\section{Risk factors associated with hypoxemia during bronchoscopy}

The independent predictors were assessed for risk factors associated with hypoxemia during bronchoscopy in the modified HFNC group via a univariate analysis. The statistically significant $(p \leq 0.1)$ variables from the univariate analysis were included in a multivariate analysis. The multivariate analysis was assessed using multiple logistic regression based on backward stepwise selection. We used a receiver operating characteristic (ROC) curve to confirm the cutoff value of patients with hypoxemia in the modified HFNC group.

All $p$ values were two-sided, and values $<0.05$ were considered significant. Data were analyzed using statistical software (SPSS 21.0; IBM Corp., Armonk, NY, USA).

\section{Results \\ Patients}

There were a total of 907 patients with indications for diagnostic bronchoscopy from November 2015 to October 2019, of whom 812 met the inclusion criteria and 95 were excluded. The remaining 812 patients were randomized to the modified HFNC $(n=406)$ or COT group $(\mathrm{n}=406)$. Among the patients in the modified HFNC and COT groups, 14 and 10 could not cooperate and comply with bronchoscopy, respectively. Thus, 788 patients were included in the final analysis (Fig. 2).

The general clinical characteristics and physiologic parameters of the patients at the time of randomization are summarized in Table 1 . The main indications for bronchoscopy were suspected lung cancer (33.0\%), nonrevolving pneumonia (20.9\%), and interstitial lung disease (20.1\%). The arterial blood gas values at the time of randomization were normal. Baseline spirometry revealed the ratio of forced expiratory volume in one second (FEV1) to forced vital capacity (FVC), and the percent of predicted diffusing capacity of lungs for carbon monoxide (DLco) was $73.4 \%$ and $78.1 \%$ lower than normal, respectively. There were no significant differences between the two groups with respect to age, sex, body mass index (BMI), smoking history, indication for bronchoscopy, vital signs, arterial blood gas values, baseline spirometry, or laboratory parameters. 


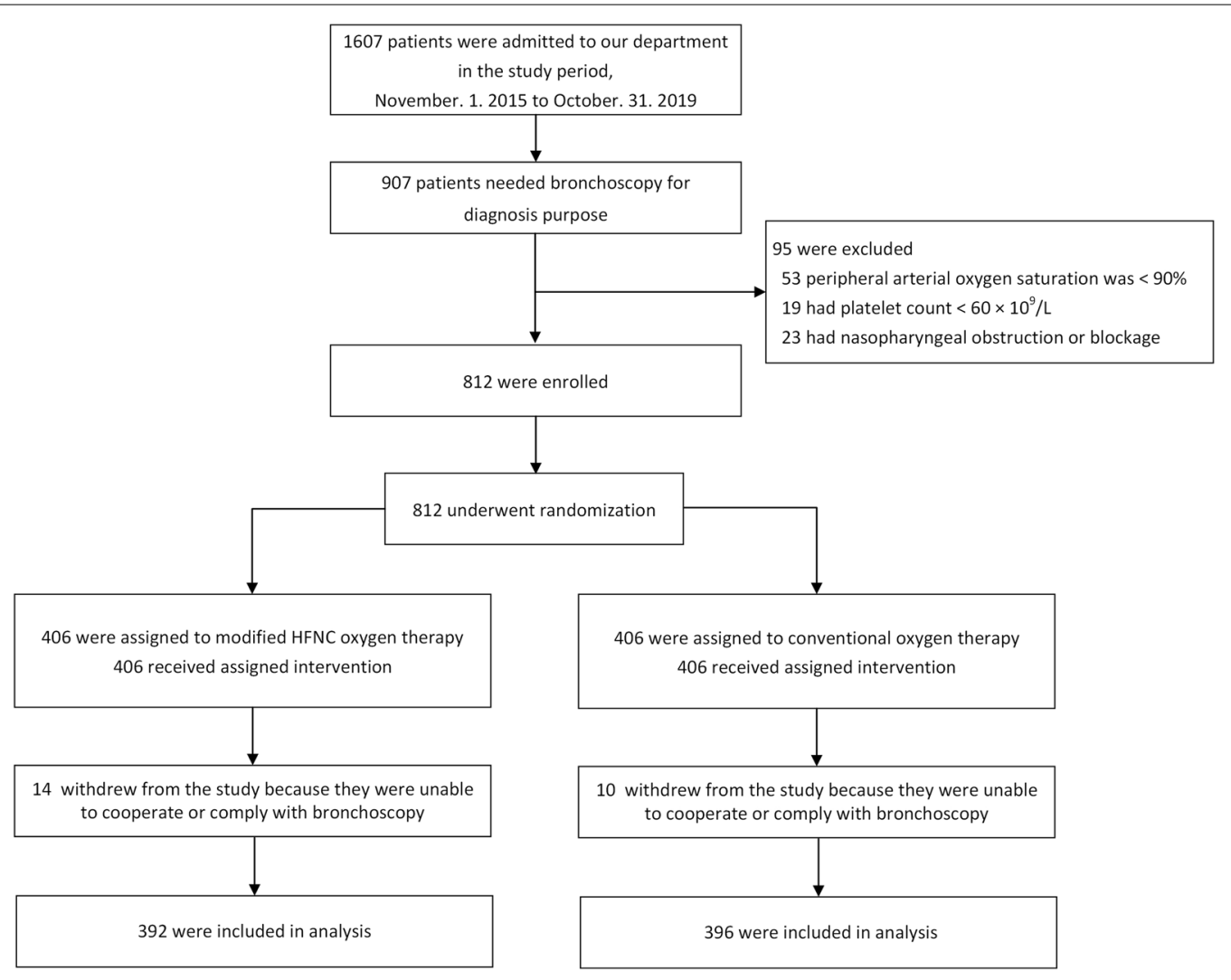

Fig. 2 Flow diagram of the trial. HFNC high-flow nasal cannula

\section{Endpoints}

Clinical endpoints of the patients are shown in Table 2. The proportion of patients with a single moment of $\mathrm{SpO}_{2}<90 \%$ during bronchoscopy in the modified HFNC group was significantly lower than that in the COT group $(12.5 \%$ vs. $28.8 \%, p<0.001)$. The duration of bronchoscopy was $685 \mathrm{~s}$ (range 485-850 s) in the modified HFNC group, which was significantly shorter than the $800 \mathrm{~s}$ (range 614-990 s) in the COT group $(p<0.001)$. The duration of $\mathrm{SpO}_{2}<90 \%$ was significantly shorter in the HFNC group. Furthermore, 102 (25.8) patients had procedural discontinuation in the COT group, while only 39 (9.9) patients in the HFNC group $(p<0.001)$.

There were no significant differences in the volume of instilled and retrieved fluid, number of bronchial brushings, endobronchial biopsies, or transbronchial lung biopsies between the two groups. Significantly fewer patients had agitation $(11.0 \%$ vs. $19.2 \%, p=0.001)$ and supraventricular tachycardias $(1.0 \%$ vs. $3.0 \%, p=0.045)$ in the modified HFNC group than in the COT group. Pneumothorax occurred in the COT group with a higher prevalence than in the modified HFNC group $(5.8 \%$ vs. $2.6 \%, p=0.022)$. There were no significant differences in other complications between the two groups.

\section{Time course of vital signs and $\mathrm{FiO}_{2}$}

Vital signs and $\mathrm{FiO}_{2}$ were monitored before, during, and after bronchoscopy. There were no significant differences in $\mathrm{FiO}_{2}$ between the two groups. The $\mathrm{SpO}_{2}$ was significantly decreased, and the $\mathrm{FiO}_{2}$, respiratory rate, heart rate, and mean arterial pressure were significantly increased during bronchoscopy in both groups (Table 3 and Fig. 3). During and $5 \mathrm{~min}$ after bronchoscopy, the $\mathrm{SpO}_{2}$ in the modified HFNC group was significantly higher than that in the COT group, and the respiratory and heart rates were significantly lower than those in the COT group. Two hours after bronchoscopy, the respiratory and heart rates and the mean arterial pressure returned to the levels before bronchoscopy, and the $\mathrm{SpO}_{2}$ slowly recovered.

\section{Risk factors associated with hypoxemia in the modified HFNC group}

Forty-nine of 392 patients in the modified HFNC group were hypoxemic during bronchoscopy. Based on multivariate logistic regression analysis, a baseline $\mathrm{FVC}<2.7 \mathrm{~L}$ (OR, 0.276; 95\% CI, 0.083-0.919, $p=0.036$ ) and volume of fluid instilled $>60 \mathrm{ml}$ (OR, 1.034; 95\% CI, 1.002-1.067, $p=0.036)$ were identified as independent risk factors 
Table 1 Characteristics of patients at randomization

\begin{tabular}{|c|c|c|c|}
\hline Characteristic & All patients $(n=788)$ & $\begin{array}{l}\text { Modified high-flow nasal cannula } \\
\text { oxygen group therapy }(\mathrm{n}=392)\end{array}$ & $\begin{array}{l}\text { Conventional oxygen } \\
\text { therapy group } \\
(\mathrm{n}=396)\end{array}$ \\
\hline Age (years) & $58.5(49.0-66.0)$ & $58.0(50.0-66.0)$ & $59.0(48.0-66.0)$ \\
\hline Male, no. (\%) & $426(54.1)$ & $204(52.4)$ & $222(56.1)$ \\
\hline Body mass index $\left(\mathrm{kg} / \mathrm{m}^{2}\right)$ & $23.7(21.1-26.0)$ & $23.7(21.3-26.0)$ & $23.6(21.0-26.1)$ \\
\hline Current smoker, no. (\%) & $173(22.0)$ & $85(21.7)$ & $88(22.2)$ \\
\hline Pack-years no & $30.0(15.0-45.0)$ & $30.0(13.5-50.0)$ & $30.0(15.0-40.0)$ \\
\hline \multicolumn{4}{|l|}{ Indication for bronchoscopy, no. (\%) } \\
\hline Hemoptysis & $87(11.0)$ & $40(10.2)$ & $47(11.9)$ \\
\hline Unexplained chronic cough & $39(4.9)$ & $22(5.6)$ & $17(4.3)$ \\
\hline Non-resolving pneumonia & $165(20.9)$ & $78(19.9)$ & $87(22.0)$ \\
\hline Pneumonia in immunocompromised host & $71(9.0)$ & $41(10.5)$ & $30(7.6)$ \\
\hline Interstitial lung disease & $158(20.1)$ & $85(21.7)$ & $73(18.4)$ \\
\hline Suspected lung cancer & $260(33.0)$ & $123(31.4)$ & $137(34.6)$ \\
\hline Foreign body aspiration & $8(1.0)$ & $3(0.8)$ & $5(1.3)$ \\
\hline \multicolumn{4}{|l|}{ Vital signs } \\
\hline Temperature, ${ }^{\circ} \mathrm{C}$ & $36.6 \pm 0.51$ & $36.6 \pm 0.49$ & $36.6 \pm 0.53$ \\
\hline Respiratory rate (beats/min) & $17 \pm 4$ & $17 \pm 5$ & $18 \pm 4$ \\
\hline Heart rate (beats/min) & $84 \pm 15$ & $84 \pm 15$ & $83 \pm 15$ \\
\hline Mean arterial pressure $(\mathrm{mmHg})$ & $93 \pm 17$ & $93 \pm 20$ & $94 \pm 13$ \\
\hline \multicolumn{4}{|l|}{ Arterial blood gas (room air) } \\
\hline $\mathrm{pH}$ & $7.42(7.40-7.44)$ & $7.42(7.40-7.44)$ & $7.42(7.39-7.44)$ \\
\hline $\mathrm{PaO}_{2}(\mathrm{mmHg})$ & $79.0(71.0-88.0)$ & $80.0(70.0-89.0)$ & $79.0(71.0-88.0)$ \\
\hline $\mathrm{PaCO}_{2}(\mathrm{mmHg})$ & $40.0(37.0-43.0)$ & $40.0(37.0-43.0)$ & $40.0(37.0-43.0)$ \\
\hline $\mathrm{HCO}_{3}^{-}(\mathrm{mmol} / \mathrm{L})$ & $24.4(21.8-27.2)$ & $24.6(22.2-26.9)$ & $23.8(21.4-27.9)$ \\
\hline $\mathrm{SaO}_{2}(\%)$ & $96.0(94.0-97.0)$ & $96.0(94.0-97.0)$ & $96.0(94.0-97.0)$ \\
\hline \multicolumn{4}{|l|}{ Baseline spirometry } \\
\hline $\mathrm{FVC}(\mathrm{L})$ & $3.08 \pm 0.95$ & $3.13 \pm 0.91$ & $3.03 \pm 0.98$ \\
\hline FEV1 (L) & $2.32 \pm 0.78$ & $2.36 \pm 0.74$ & $2.28 \pm 0.82$ \\
\hline FEV1 (\% predicted) & $82.7 \pm 12.7$ & $81.3 \pm 13.3$ & $83.9 \pm 12.2$ \\
\hline FEV1/FVC (\%) & $73.4 \pm 12.8$ & $73.7 \pm 12.0$ & $73.2 \pm 13.2$ \\
\hline DLco (\% predicted) & $78.1 \pm 9.9$ & $77.9 \pm 9.5$ & $78.4 \pm 10.3$ \\
\hline \multicolumn{4}{|l|}{ Laboratory parameters } \\
\hline White blood cell $\left(\times 10^{9} / \mathrm{L}\right)$ & $6.59(5.23-8.27)$ & $6.34(5.07-8.25)$ & $6.79(5.34-8.33)$ \\
\hline Platelet count $\left(\times 10^{9} / \mathrm{L}\right)$ & $237(194-293)$ & $232(192-288)$ & $242(196-300)$ \\
\hline Prothrombin time (s) & $11.2(9.9-12.6)$ & $11.1(10.0-12.4)$ & $11.3(9.8-12.7)$ \\
\hline Fibrinogen (mg/dL) & $285.1 \pm 104.1$ & $283.6 \pm 104.6$ & $286.6 \pm 103.7$ \\
\hline C-reactive protein (mg/dL) & $0.8(0.5-1.2)$ & $0.8(0.5-1.1)$ & $0.8(0.5-1.2)$ \\
\hline Procalcitonin (pg/ml) & $0.10(0.08-0.12)$ & $0.10(0.08-0.11)$ & $0.10(0.08-0.12)$ \\
\hline
\end{tabular}

$\mathrm{PaO}_{2}$, partial pressure of arterial oxygen; $\mathrm{PaCO}_{2}$, partial pressure of arterial carbon dioxide; $\mathrm{HCO}_{3}{ }^{-}$, bicarbonate; SaO ${ }_{2}$, arterial oxygen saturation; $\mathrm{FVC}$, forced vital capacity; FEV1, forced expiratory volume in one second; DLCo, diffusing capacity of lungs for carbon monoxide

associated with hypoxemia during bronchoscopy in the modified HFNC group (Table 4).

\section{Discussion}

In this study, we showed that, compared with oxygen therapy by nasal cannula, modified HFNC significantly prevented the incidence of hypoxia and shortened the duration of bronchoscopy. The modified HFNC reduced the occurrence of agitation and arrhythmias during bronchoscopy. In addition, baseline $\mathrm{FVC}<2.7 \mathrm{~L}$ and volume of fluid instilled $>60 \mathrm{ml}$ were independently associated with hypoxemia during bronchoscopy.

HFNC oxygen therapy has become increasingly popular in the treatment of patients with various clinical 
Table 2 Clinical endpoints, bronchoscopy-related events, and complications according to study group

\begin{tabular}{|c|c|c|c|c|}
\hline Outcome & All patients $(n=788)$ & $\begin{array}{l}\text { Modified high-flow nasal } \\
\text { cannula oxygen group therapy } \\
(\mathrm{n}=392)\end{array}$ & $\begin{array}{l}\text { Conventional nasal } \\
\text { cannula oxygen group } \\
(n=396)\end{array}$ & $P$ \\
\hline \multicolumn{5}{|l|}{ Primary end point } \\
\hline $\begin{array}{l}\text { The number of patients with a single moment } \\
\text { of } \mathrm{SpO}_{2}<90 \% \text { during bronchoscopy, no. (\%) }\end{array}$ & $163(20.7)$ & $49(12.5)$ & $114(28.8)$ & $<0.001$ \\
\hline \multicolumn{5}{|l|}{ Secondary endpoint } \\
\hline Duration of bronchoscopy (s) & $780(592-965)$ & $685(485-850)$ & $800(614-990)$ & $<0.001$ \\
\hline \multicolumn{5}{|l|}{ Other endpoints } \\
\hline Duration of $\mathrm{SpO}_{2}<90 \%$ (s) & $98(29-130)$ & $22(14-27)$ & $115(96-137)$ & $<0.001$ \\
\hline $\begin{array}{l}\text { The number of patients with procedural } \\
\text { discontinuation no. (\%) }\end{array}$ & $141(17.9)$ & $39(9.9)$ & $102(25.8)$ & $<0.001$ \\
\hline \multicolumn{5}{|l|}{ Bronchoalveolar lavage } \\
\hline Volume of fluid instilled (ml) & $60(40-100)$ & $60(40-100)$ & $60(40-100)$ & 0.751 \\
\hline Volume of fluid recovered (ml) & $20(15-45)$ & $22(15-45)$ & $20(15-45)$ & 0.483 \\
\hline Bronchial brushing, no. (\%) & $736(93.4)$ & 367 (93.6) & $369(93.2)$ & 0.803 \\
\hline Endobronchial biopsy, no. (\%) & $677(85.9)$ & $337(86.0)$ & $340(85.9)$ & 0.964 \\
\hline Transbronchial lung biopsy, no. (\%) & $235(29.8)$ & $115(29.3)$ & $120(30.3)$ & 0.767 \\
\hline \multicolumn{5}{|l|}{ Events during bronchoscopy, no. (\%) } \\
\hline Agitation & $119(15.1)$ & $43(11.0)$ & $76(19.2)$ & 0.001 \\
\hline Bronchospasm & $30(3.8)$ & $12(3.1)$ & $18(4.5)$ & 0.276 \\
\hline \multicolumn{5}{|l|}{ Arrhythmias } \\
\hline Ventricular arrhythmias & $8(1.0)$ & $3(0.8)$ & $5(1.3)$ & 0.484 \\
\hline Supraventricular tachycardias & $16(2.0)$ & $4(1.0)$ & $12(3.0)$ & 0.045 \\
\hline Premature atrial contractions & $25(3.2)$ & $11(2.8)$ & $14(3.5)$ & 0.559 \\
\hline Premature ventricular contraction & $14(1.8)$ & $5(1.3)$ & $9(2.3)$ & 0.289 \\
\hline $\begin{array}{l}\text { Hypertension (systolic blood pres- } \\
\text { sure }>180 \mathrm{mmHg} \text { ) }\end{array}$ & $124(15.7)$ & $64(16.3)$ & $60(15.2)$ & 0.651 \\
\hline Epistaxis & $40(5.1)$ & $18(4.6)$ & $22(5.6)$ & 0.538 \\
\hline Mucosal bleeding & $204(25.9)$ & $103(26.3)$ & $101(25.5)$ & 0.805 \\
\hline \multicolumn{5}{|l|}{ Complications of bronchoscopy, no. (\%) } \\
\hline Fever & $162(20.6)$ & $78(19.9)$ & $84(21.2)$ & 0.648 \\
\hline Pneumothorax & $33(4.2)$ & $10(2.6)$ & $23(5.8)$ & 0.022 \\
\hline Hemorrhage & $51(6.5)$ & $25(6.4)$ & $26(6.6)$ & 0.915 \\
\hline
\end{tabular}

$\mathrm{SpO}_{2}$, peripheral arterial oxygen saturation

conditions [17]. It has been proposed that HFNC oxygen therapy provides several benefits [18]. Among these benefits are maintenance of a constant $\mathrm{FiO}_{2}$, generation of a positive end-expiratory pressure (PEEP), reduction in the anatomic dead space, improvement of mucociliary clearance, and decreased work of breathing.

As a new type of oxygen therapy, several studies have involved the use of HFNC as a support for oxygen supplementation during bronchoscopy. A recent study showed that HFNC provides better oxygenation than standard therapy, prevents lung de-recruitment, and avoids the increase of diaphragm activation during bronchoscopy for BAL. Compared with the standard therapy group, fewer desaturations occurred $(11 \%$ vs. $56 \% ; p<0.01)$ in the HFNC group [19]. It aligns with our observation. In patients undergoing endobronchial ultrasound-guided transbronchial needle aspiration (EBUS-TBNA), HFNC could prevent desaturation compared with standard oxygen therapy [20, 21]. In addition, HFNC can also be used for lung transplant patients to reduce the proportion of hypoxemia during bronchoscopy [22].

HFNC oxygen therapy, however, has some shortcomings with respect to transnasal bronchoscopy. HFNC oxygen therapy is applied to both nostrils, and the narrowing of the lumen influences the flow in the nostril in which the bronchoscope is inserted. Lower flow affects the level of PEEP generated [23]. Moreover, when the patient's inspiratory flow rates exceed the flow delivered during bronchoscopy, the additional flow is recruited from the surrounding air $\left(\mathrm{FiO}_{2}=0.21\right)$. In this situation, 
Table 3 Comparison of vital signs between the modified high-flow nasal cannula oxygen and the conventional oxygen therapy groups

\begin{tabular}{|c|c|c|c|c|c|c|c|c|c|}
\hline Characteristic & Group & $\begin{array}{l}\text { Pre-5 min } \\
(n=392 / 396)\end{array}$ & $\begin{array}{l}\text { The lowest } \\
\mathrm{SpO}_{2} \text {, the } \\
\text { highest } \\
\text { respiratory } \\
\text { rate, heart } \\
\text { rate, and } \\
\text { mean arterial } \\
\text { pressure } \\
(\mathrm{n}=392 / 396)\end{array}$ & $\begin{array}{l}\text { Post-5 min } \\
(n=392 / 396)\end{array}$ & $\begin{array}{l}\text { Post-10 min } \\
(n=392 / 396)\end{array}$ & $\begin{array}{l}\text { Post-2 h } \\
(n=392 / 396)\end{array}$ & $\begin{array}{l}\text { Post-6 h } \\
(n=392 / 396)\end{array}$ & $\begin{array}{l}\text { Post-24 h } \\
(n=392 / 396)\end{array}$ & $p^{a}$ \\
\hline \multirow[t]{3}{*}{$\mathrm{SpO}_{2}(\%)$} & MHFNC & $97.4 \pm 1.6$ & $94.1 \pm 3.2$ & $95.4 \pm 2.3$ & $94.7 \pm 2.7$ & $95.5 \pm 1.8$ & $95.7 \pm 1.8$ & $96.0 \pm 1.7$ & $<0.001$ \\
\hline & Control & $97.3 \pm 1.5$ & $90.5 \pm 3.8$ & $92.1 \pm 2.6$ & $93.4 \pm 2.9$ & $95.3 \pm 2.1$ & $95.7 \pm 1.9$ & $95.9 \pm 1.8$ & $<0.001$ \\
\hline & $p^{c}$ & 0.268 & $<0.001$ & $<0.001$ & $<0.001$ & 0.348 & 0.869 & 0.493 & $0.003^{b}$ \\
\hline \multirow{3}{*}{$\begin{array}{l}\text { Respiratory } \\
\text { rate (bpm) }\end{array}$} & MHFNC & $17 \pm 5$ & $26 \pm 7$ & $19 \pm 5$ & $19 \pm 4$ & $18 \pm 3$ & $17 \pm 3$ & $17 \pm 3$ & $<0.001$ \\
\hline & Control & $18 \pm 4$ & $28 \pm 6$ & $21 \pm 5$ & $20 \pm 4$ & $18 \pm 3$ & $17 \pm 3$ & $17 \pm 3$ & $<0.001$ \\
\hline & $p^{c}$ & 0.196 & $<0.001$ & $<0.001$ & 0.005 & 0.693 & 0.694 & 0.973 & $0.001^{b}$ \\
\hline \multirow{3}{*}{$\begin{array}{l}\text { Heart rate } \\
\text { (beats/min) }\end{array}$} & MHFNC & $84 \pm 15$ & $112 \pm 18$ & $94 \pm 16$ & $93 \pm 16$ & $83 \pm 10$ & $82 \pm 10$ & $81 \pm 10$ & $<0.001$ \\
\hline & Control & $83 \pm 15$ & $116 \pm 21$ & $97 \pm 18$ & $94 \pm 16$ & $82 \pm 10$ & $81 \pm 11$ & $80 \pm 10$ & $<0.001$ \\
\hline & $p^{c}$ & 0.305 & 0.015 & 0.037 & 0.377 & 0.167 & 0.818 & 0.334 & $0.465^{b}$ \\
\hline \multirow{3}{*}{$\begin{array}{l}\text { Mean arterial } \\
\text { pressure } \\
(\mathrm{mmHg})\end{array}$} & MHFNC & $95 \pm 13$ & $108 \pm 15$ & $102 \pm 14$ & $104 \pm 17$ & $95 \pm 10$ & $94 \pm 10$ & $94 \pm 9$ & $<0.001$ \\
\hline & Control & $94 \pm 12$ & $110 \pm 18$ & $103 \pm 16$ & $104 \pm 16$ & $96 \pm 10$ & $95 \pm 10$ & $94 \pm 10$ & $<0.001$ \\
\hline & $p^{c}$ & 0.454 & 0.256 & 0.233 & 0.890 & 0.541 & 0.342 & 0.580 & $0.402^{b}$ \\
\hline
\end{tabular}

$\mathrm{FiO}_{2}$ the fraction of inspired oxygen, $\mathrm{SpO}_{2}$ peripheral arterial oxygen saturation

$p^{a}$ for overall comparisons of differences in each group over time

$p^{b}$ for overall comparisons of differences between groups over time

$p^{c}$ for comparisons of differences between groups at each time point

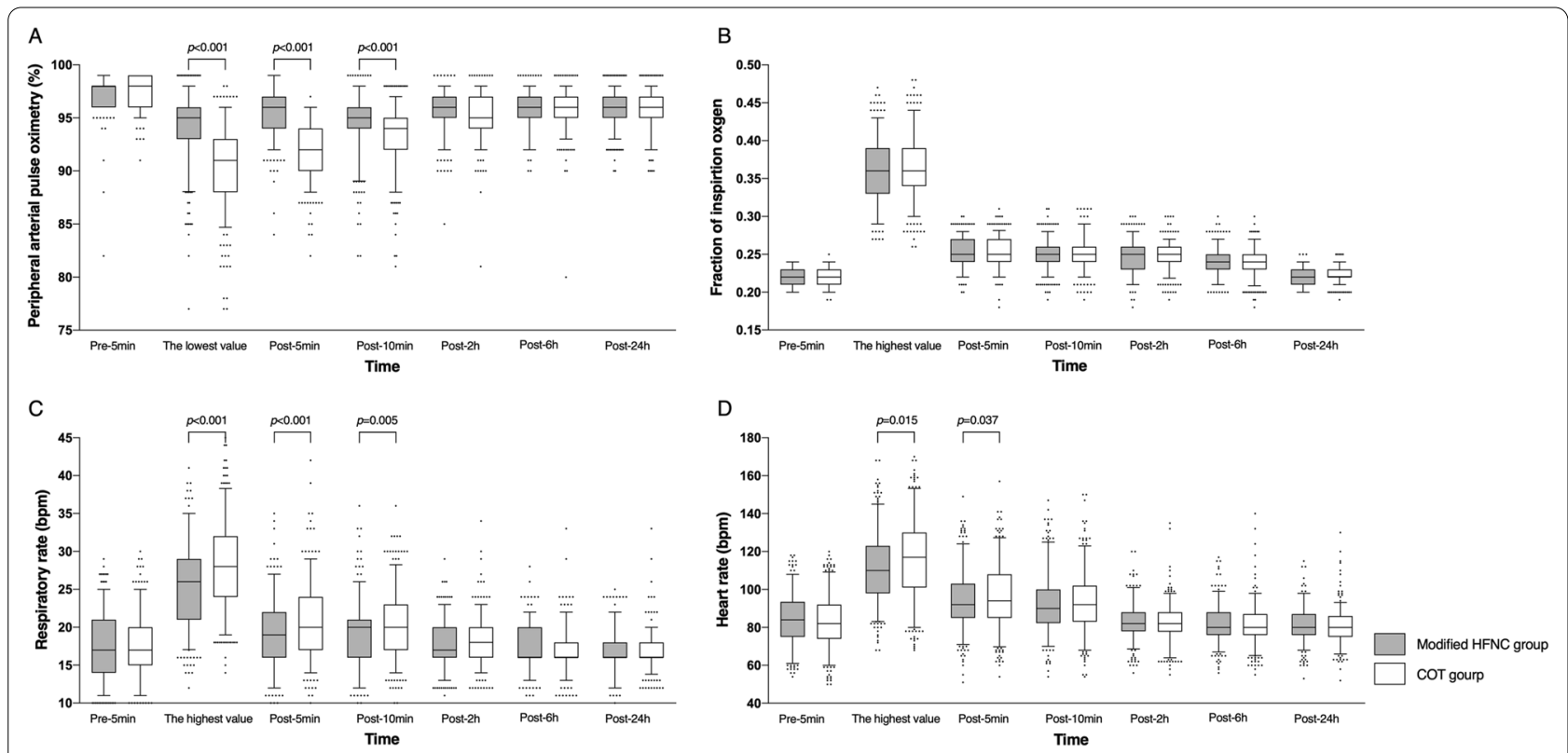

Fig. 3 Comparison of vital signs and $\mathrm{FiO}_{2}$ between the modified HFNC and COT groups. HFNC high-flow nasal cannula, COT conventional oxygen therapy 
Table 4 Risk factors associated with hypoxemia during bronchoscopy in modified high-flow nasal cannula oxygen group

\begin{tabular}{|c|c|c|c|c|}
\hline Variable & $\beta$ coefficient & Standard error & Odds ratios $(95 \% \mathrm{Cl})$ & $P$ \\
\hline \multicolumn{5}{|l|}{ Univariate logistic regression } \\
\hline Baseline $\mathrm{PaO}_{2}$ & -0.027 & 0.012 & $0.973(0.950-0.996)$ & 0.024 \\
\hline Baseline $\mathrm{SaO}_{2}$ & -0.199 & 0.069 & $0.820(0.716-0.939)$ & 0.004 \\
\hline Baseline FVC & -1.027 & 0.456 & $0.356(0.147-0.875)$ & 0.024 \\
\hline Volume of fluid instilled & 0.011 & 0.004 & $1.012(1.003-1.020)$ & 0.005 \\
\hline Hemorrhage & 0.715 & 0.337 & $2.044(1.055-3.959)$ & 0.034 \\
\hline \multicolumn{5}{|l|}{ Multivariate logistic regression } \\
\hline Baseline FVC & -1.286 & 0.613 & $0.276(0.083-0.919)$ & 0.036 \\
\hline Volume of fluid instilled & 0.034 & 0.016 & $1.034(1.002-1.067)$ & 0.036 \\
\hline
\end{tabular}

$\mathrm{PaO}_{2}$, partial pressure of arterial oxygen; $\mathrm{SaO}_{2}$, arterial oxygen saturation; $\mathrm{FVC}$, forced vital capacity

the inspired $\mathrm{FiO}_{2}$ is significantly lower than that of the delivered gas [24]. Therefore, we designed a modified HFNC that has a single cannula. The bronchoscope passes through one nostril of the patient, and modified HFNC oxygen therapy is given through the contralateral nostril. Compared with the unmodified version of the HFNC, the air flow passes through the single nasal cannula faster with the same flow rate. Based on the results of an in vitro study (Additional file 1), the modified HFNC has similar respiratory support characteristics as the regular HFNC under different respiratory conditions. Furthermore, the modified HFNC provides higher PEEP at high-flow rates.

Hypoxemia during bronchoscopy is common [25]. Due to partial occlusion of the airway by the bronchoscope, respiratory mechanics are altered [26]. As a result, oxygen saturation may decrease to $<90 \%$ despite oxygen supplementation. In the current study, compared with the nasal cannula, the modified HFNC decreased the incidence of hypoxemia during bronchoscopy. It is conceivable that two factors accounted for this finding. First, the $\mathrm{FiO}_{2}$ value was more stable and reliable because of reduced losses and the minimization of ambient air entrainment [27]. Second, the PEEP generated by high-flow rates may prevent alveolar collapse, improving dynamic compliance and oxygenation. This study is of certain clinical relevance, but the modified HFNC cannot entirely resolve the problem of hypoxemia during bronchoscopy. Although the $\mathrm{FiO}_{2}$ in the COT group was estimated rather than accurately measured, the results of the empirical formula are relatively accurate at low flow rates. We have also noticed that $\mathrm{FiO}_{2}$ is highly variable with breathing changes that result in greater amounts of entrained room air (increased respiratory rate, tidal volume, and inspiratory force) in the COT group. In theory, COT can only provide $24 \%-45 \%$ oxygen with flow rates up to $6 \mathrm{~L} / \mathrm{min}$. In order that the COT was comparable to modified HFNC, we did not adjust the $\mathrm{FiO}_{2}$ very high in the modified HFNC group during bronchoscopy (e.g., >0.5). Using approximately the same $\mathrm{FiO}_{2}$, the modified HFNC was able to stabilize oxygenation maintenance during bronchoscopy, avoiding discontinuation of the procedure due to hypoxemia. Therefore, the duration of bronchoscopy was shorter in the modified HFNC group. Moreover, fewer patients with agitation could decrease the frequency of pneumothorax.

NIV can also prevent hypoxemia during bronchoscopy, but facemask intolerance and difficulty manipulating the scope through the mask limit its appeal. Previous studies have shown that NIV provides greater adequacy and stability of oxygenation than HFNC treatment in hypoxemic patients undergoing bronchoscopy $[10,13]$. Therefore, NIV treatment provides better effectiveness for oxygen supplementation during bronchoscopy in patients with hypoxemia. Nevertheless, HFNC therapy is more comfortable and easier for bronchoscopists to apply than NIV.

Fiberoptic bronchoscopy with BAL is an important tool for determining the etiology of pneumonia, but BAL has significant risks for oxygenation deterioration [28]. In the current study, a $>60 \mathrm{ml}$ volume of fluid instilled was identified as an independent risk factor associated with hypoxemia during bronchoscopy in the modified HFNC group. A large volume of BAL is bound to affect gas exchange, which leads to hypoxemia in patients. Various studies, mainly involving hypoxemic patients, also showed that BAL may worsen the decrease in $\mathrm{PaO}_{2}$ during bronchoscopy $[29,30]$. In addition, we found that a baseline $\mathrm{FVC}<2.7 \mathrm{~L}$ was an independent risk factor for hypoxemia during bronchoscopy in the modified HFNC group. Patients with a lower FVC generally had different chronic respiratory diseases, and these patients were prone to hypoxemia during bronchoscopy. Therefore, we believe that an adequate baseline FVC is necessary to avoid hypoxemia during bronchoscopy. 
Mildly hypoxemic participants included in our study had $\mathrm{SpO}_{2}>90 \%$, and the $\mathrm{FiO}_{2}$ was adjusted in a timely manner during bronchoscopy. In addition, all bronchoscopy procedures were performed by three experienced respiratory specialists. Therefore, the incidence of hypoxemia in all patients was only $20.7 \%$.

Guidelines suggest sedation should be offered to patients [6]. However, all patients in our study were given topical anesthesia, but not intravenous sedation. Our approach is similar to previous studies using topical anesthesia instead of sedation $[19,31]$. The sedative can affect the airway tone and respiratory drive. Avoiding the use of sedatives in our study, we ruled out the confounding factors that could influence gas exchange.

Our trial had several limitations. First, the study had a single-blind design. Therefore, chance or unintentional treatment decision bias could not be completely eliminated; however, the treatments were strictly implemented according to the protocols in each group. Second, our study did not include patients with acute respiratory failure; thus, the benefit of the modified HFNC for such patients could not be determined and will be included in future work. Third, there were more patients with agitation and pneumothorax in the COT group. Increased agitation and pneumothorax may also have contributed to more hypoxemic events. Therefore, these confounders affect the duration of bronchoscopy. Forth, the $\mathrm{FiO}_{2}$ estimated by the empirical formula in the COT group may be inaccurate, particularly in the setting of increased work of breathing and introduction of the bronchoscope. Fifth, this study lacks exploring the physiological mechanism of avoiding hypoxemia by HFNC, such as the change of end-expiratory lung volume during bronchoscopy.

\section{Conclusions}

In conclusion, the findings from this randomized controlled trial suggest that a modified HFNC could decrease the proportion of patients with a single moment of $\mathrm{SpO}_{2}<90 \%$ during bronchoscopy and shorten the duration of bronchoscopy. A lower baseline FVC and large-volume BAL may predict hypoxemia during bronchoscopy with a modified HFNC. However, due to study limitations, high-quality randomized controlled trials further investigating the efficacy and safety of modified HFNC therapy in acute respiratory failure patients are warranted.

\footnotetext{
Abbreviations

$\mathrm{PaO}_{2}$ : Partial pressure of arterial oxygen; BAL: Bronchoalveolar lavage; $\mathrm{SaO}_{2}$ : Arterial oxygen saturation; NIV: Noninvasive ventilation; HFNC: High-flow nasal cannula; $\mathrm{SpO}_{2}$ : Peripheral arterial oxygen saturation; $\mathrm{COT}$ : Conventional oxygen therapy; $\mathrm{FiO}_{2}$ : Fraction of inspired oxygen; BMI: Body mass index; ROC: Receiver operating characteristic; FEV1: Forced expiratory volume in one second; FVC: Forced vital capacity; DLco: Diffusing capacity of lungs for carbon
}

monoxide; PEEP: Positive end-expiratory pressure; EBUS-TBNA: Endobronchial ultrasound-guided transbronchial needle aspiration.

\section{Supplementary Information}

The online version contains supplementary material available at https://doi. org/10.1186/s12890-021-01744-8.

Additional file 1. 1. Methods. 1.1 Appendix S1: Assessment of the modified HFNC in vitro test. 2. Tables. 2.1 Table S1: The combination of parameters defines a state by TestChest. 2.2 Table S2: Effect of modified and regular HFNC on PEEP. 2.3 Table S3: Effect of modified and regular HFNCS on tidal volumes. 2.4 Table S4: Effect of modified and regular HFNCs on $\mathrm{FiO} 2$ (FiO2 set at 50\%). 3.1 Figure S1: Modified high-flow nasal cannula. 3.2 Figure S2: Device connection diagram.

\section{Acknowledgements}

Not applicable.

\section{Authors' contributions}

RW and $\mathrm{HCL}$ contributed substantially to the research design, recruited patients to the study, participated in the acquisition of data, wrote the first draft of the manuscript and edited the manuscript after feedback from coauthors. XYL, TX, HWC, XY, and ZHT contributed substantially to the treatment of patients in the study, participated in acquisition of the data, and provided revisions to the manuscript. BS contributed substantially to the research design, monitored and organized the study, recruited patients to the study, participated in acquisition and analysis of the data, wrote the first draft of the manuscript and edited the manuscript after feedback from coauthors. All authors read and approved the final manuscript.

\section{Funding}

The authors received no funding for this study.

\section{Availability of data and materials}

The datasets used and/or analyzed during the current study are available from the corresponding author on reasonable request.

\section{Declarations}

Ethics approval and consent to participate

This study was approved by the Ethics Committee of the Affiliated Beijing Chao-Yang Hospital, Capital Medical University (2015-KE-85), and informed consent was obtained from all patients or their legal guardians in writing.

\section{Consent for publication}

Not applicable.

\section{Competing interests}

The authors declare that they have no competing interests.

Received: 7 July 2021 Accepted: 11 November 2021

Published online: 14 November 2021

\section{References}

1. Du Rand IA, Barber PV, Goldring J, Lewis RA, Mandal S, Munavvar M, Rintoul RC, Shah PL, Singh S, Slade MG, et al. Summary of the British Thoracic Society guidelines for advanced diagnostic and therapeutic flexible bronchoscopy in adults. Thorax. 2011;66(11):1014-5.

2. Criner GJ, Eberhardt R, Fernandez-Bussy S, Gompelmann D, Maldonado F, Patel N, Shah PL, Slebos DJ, Valipour A, Wahidi MM, et al. Interventional bronchoscopy. Am J Respir Crit Care Med. 2020;202(1):29-50.

3. Kvale PA. Prevention and management of hypoxemia during fiberoptic bronchoscopy. Chest. 2002;121(4):1021-2.

4. Du Rand IA, Blaikley J, Booton R, Chaudhuri N, Gupta V, Khalid S, Mandal S, Martin J, Mills J, Navani N, et al. British Thoracic Society guideline for 
diagnostic flexible bronchoscopy in adults: accredited by NICE. Thorax. 2013;68(Suppl 1):i1-44.

5. Jones AM, O'Driscoll R. Do all patients require supplemental oxygen during flexible bronchoscopy? Chest. 2001;119(6):1906-9.

6. British Thoracic Society Bronchoscopy Guidelines Committee aSoSoCCoBTS. British Thoracic Society guidelines on diagnostic flexible bronchoscopy. Thorax. 2001;56(Suppl 1):i1-21.

7. Antonelli M, Conti G, Rocco M, Arcangeli A, Cavaliere F, Proietti R, Meduri GU. Noninvasive positive-pressure ventilation vs. conventional oxygen supplementation in hypoxemic patients undergoing diagnostic bronchoscopy. Chest. 2002;121(4):1149-54

8. Cracco C, Fartoukh M, Prodanovic H, Azoulay E, Chenivesse C, Lorut C, Beduneau G, Bui HN, Taille C, Brochard L, et al. Safety of performing fiberoptic bronchoscopy in critically ill hypoxemic patients with acute respiratory failure. Intensive Care Med. 2013;39(1):45-52.

9. Cuquemelle E, Pham T, Papon JF, Louis B, Danin PE, Brochard L. Heated and humidified high-flow oxygen therapy reduces discomfort during hypoxemic respiratory failure. Respir Care. 2012;57(10):1571-7.

10. Simon M, Braune S, Frings D, Wiontzek AK, Klose H, Kluge S. High-flow nasal cannula oxygen versus non-invasive ventilation in patients with acute hypoxaemic respiratory failure undergoing flexible bronchoscopy—a prospective randomised trial. Crit Care. 2014;18(6):712.

11. Kim EJ, Jung CY, Kim KC. Effectiveness and safety of high-flow nasal cannula oxygen delivery during bronchoalveolar lavage in acute respiratory failure patients. Tuberc Respir Dis (Seoul). 2018;81 (4):319-29.

12. Beng Leong L, Wei Ming N, Wei Feng L. High flow nasal cannula oxygen versus noninvasive ventilation in adult acute respiratory failure: a systematic review of randomized-controlled trials. Eur J Emerg Med. 2019;26(1):9-18.

13. Saksitthichok B, Petnak T, So-Ngern A, BoonsarngsukV. A prospective randomized comparative study of high-flow nasal cannula oxygen and non-invasive ventilation in hypoxemic patients undergoing diagnostic flexible bronchoscopy. J Thorac Dis. 2019;11(5):1929-39.

14. Aarc: AARC clinical practice guideline. Oxygen therapy in the home or alternate site health care facility -2007 revision \& update. Respir Care. 2007;52(8):1063-8.

15. Sharif-Kashani B, Shahabi P, Behzadnia N, Mohammad-Taheri Z, Mansouri D, Masjedi MR, Zargari L, Salimi Negad L. Incidence of fever and bacteriemia following flexible fiberoptic bronchoscopy: a prospective study. Acta Med Iran. 2010;48(6):385-8.

16. Milman N, Faurschou P, Grode G, Jorgensen A. Pulse oximetry during fibreoptic bronchoscopy in local anaesthesia: frequency of hypoxaemia and effect of oxygen supplementation. Respiration. 1994;61(6):342-7.

17. Li J, Jing G, Scott JB. Year in review 2019: high-flow nasal cannula oxygen therapy for adult subjects. Respir Care. 2020;65(4):545-57.

18. Helviz Y, Einav S. A systematic review of the high-flow nasal cannula for adult patients. Crit Care. 2018;22(1):71.

19. Longhini F, Pelaia C, Garofalo E, Bruni A, Placida R, laquinta C, Arrighi E, Perri G, Procopio G, Cancelliere A, et al. High-flow nasal cannula oxygen therapy for outpatients undergoing flexible bronchoscopy: a randomised controlled trial. Thorax. 2021. https://doi.org/10.1136/thora xinl-2021-217116

20. Douglas N, Ng I, Nazeem F, Lee K, Mezzavia P, Krieser R, Steinfort D, Irving $L$, Segal R. A randomised controlled trial comparing high-flow nasal oxygen with standard management for conscious sedation during bronchoscopy. Anaesthesia. 2018;73(2):169-76.

21. Irfan M, Ahmed M, Breen D. Assessment of high flow nasal cannula oxygenation in endobronchial ultrasound bronchoscopy: a randomized controlled trial. J Bronchol Interv Pulmonol. 2021;28(2):130-7.

22. Ben-Menachem E, McKenzie J, O'Sullivan C, Havryk AP. High-flow nasal oxygen versus standard oxygen during flexible bronchoscopy in lung transplant patients: a randomized controlled trial. J Bronchol Interv Pulmonol. 2020;27(4):259-65.

23. Groves $N$, Tobin A. High flow nasal oxygen generates positive airway pressure in adult volunteers. Aust Crit Care. 2007;20(4):126-31.

24. Nishimura M. High-flow nasal cannula oxygen therapy in adults. J Intensive Care. 2015;3(1):15.

25. Albertini R, Harrel JH, Moser KM. Letter: hypoxemia during fiberoptic bronchoscopy. Chest. 1974:65(1):117-8.

26. Matsushima Y, Jones RL, King EG, Moysa G, Alton JD. Alterations in pulmonary mechanics and gas exchange during routine fiberoptic bronchoscopy. Chest. 1984;86(2):184-8.

27. Spoletini G, Alotaibi M, Blasi F, Hill NS. Heated humidified high-flow nasal oxygen in adults: mechanisms of action and clinical implications. Chest. 2015;148(1):253-61.

28. Lindholm CE, Ollman B, Snyder J, Millen E, Grenvik A. Flexible fiberoptic bronchoscopy in critical care medicine. Diagnosis, therapy and complications. Crit Care Med. 1974;2(5):250-61.

29. Maitre B, Jaber S, Maggiore SM, Bergot E, Richard JC, Bakthiari H, Housset $B$, Boussignac $G$, Brochard L. Continuous positive airway pressure during fiberoptic bronchoscopy in hypoxemic patients. A randomized doubleblind study using a new device. Am J Respir Crit Care Med. 2000;162(3 Pt 1):1063-7.

30. Turner JS, Willcox PA, Hayhurst MD, Potgieter PD. Fiberoptic bronchoscopy in the intensive care unit-a prospective study of 147 procedures in 107 patients. Crit Care Med. 1994;22(2):259-64.

31. Antonelli M, Pennisi MA, Conti G, Bello G, Maggiore SM, Michetti V, Cavaliere F, Proietti R. Fiberoptic bronchoscopy during noninvasive positive pressure ventilation delivered by helmet. Intensive Care Med. 2003;29(1):126-9

\section{Publisher's Note}

Springer Nature remains neutral with regard to jurisdictional claims in published maps and institutional affiliations.
Ready to submit your research? Choose BMC and benefit from:

- fast, convenient online submission

- thorough peer review by experienced researchers in your field

- rapid publication on acceptance

- support for research data, including large and complex data types

- gold Open Access which fosters wider collaboration and increased citations

- maximum visibility for your research: over $100 \mathrm{M}$ website views per year

At BMC, research is always in progress.

Learn more biomedcentral.com/submissions 